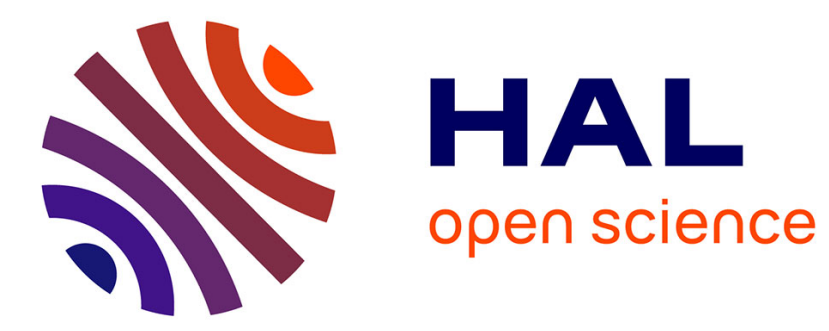

\title{
Preparation and properties of coiled carbon fibers by the catalitic pyrolysis of acetylene
}

S. Motojima, I. Hasegawa, S. Kagiya, S. Asakura, M. Kawaguchi, H. Iwanaga

\section{To cite this version:}

S. Motojima, I. Hasegawa, S. Kagiya, S. Asakura, M. Kawaguchi, et al.. Preparation and properties of coiled carbon fibers by the catalitic pyrolysis of acetylene. Journal de Physique IV Proceedings, 1993, 03 (C3), pp.C3-599-C3-606. 10.1051/jp4:1993383 . jpa-00251440

\section{HAL Id: jpa-00251440 https://hal.science/jpa-00251440}

Submitted on 1 Jan 1993

HAL is a multi-disciplinary open access archive for the deposit and dissemination of scientific research documents, whether they are published or not. The documents may come from teaching and research institutions in France or abroad, or from public or private research centers.
L'archive ouverte pluridisciplinaire HAL, est destinée au dépôt et à la diffusion de documents scientifiques de niveau recherche, publiés ou non, émanant des établissements d'enseignement et de recherche français ou étrangers, des laboratoires publics ou privés. 


\title{
Preparation and properties of coiled carbon fibers by the catalitic pyrolysis of acetylene
}

\author{
S. MOTOJIMA, I. HASEGAWA, S. KAGIYA, S. ASAKURA, M. KAWAGUCH* and H. IWANAGA**
}

Department of Applied Chemistry, Faculty of Engineering, Gifu University, Gifu 501-11, Japan

* Central Glass Co. Ltd., Japan

${ }^{* *}$ Nagasaki University, Japan

Abstract-Microcoiled carbon fibers were obtained by the $\mathrm{Ni}$ catalyzed pyrolysis of acetylene at $600-800^{\circ} \mathrm{C}$. The presence of small amounts of a sulfur compound impurity was indispensable for the growth of the coiled carbon fibers in high yield with good reproducibility. The optimum growth temperature was $750^{\circ} \mathrm{C}$ irrespective of the kind of sulfur compounds used as the impurity. The optimum impurity gas flow rate was restricted to a very narrow range depending on the impurity type. The maximum yield (about $50 \%$ ) of the coiled carbon fibers was obtained using thiophene. Some properties of the coiled carbon fibers were examined. A new growth mechanism for the coiled carbon fibers will be presented.

\section{Introduction}

Coiled inorganic whiskers or fibers are very interesting in relation to their peculiar morphology and growth mechanism as well as their novel applications. We have reported that regularly-coiled silicon nitride fibers were obtained from a gas mixture of $\mathrm{Si}_{2} \mathrm{Cl}_{6}+\mathrm{NH}_{3}+\mathrm{H}_{2}+\mathrm{Ar}$ at $1200^{\circ} \mathrm{C}$ using an iron impurity as the catalyst $(1,2)$. It has been observed that some of the vapor-grown carbon fibers coiled helically (3-10). However, the detailed growth conditions, morphology and growth mechanism as we11 as their properties have not been examined. Recently, we obtained micro-coiled carbon fibers by the catalytic pyrolysis of acetylene at $600-800^{\circ} \mathrm{C}$ using $\mathrm{Ni}$ powder as the catalyst (11-14).

In this work, the micro-coiled carbon fibers were obtained on a graphite substrate by the Ni-catalyzed pyrolysis of acetylene in the presence of a small amount of sulfur-based impurities. The effects of the kind of sulfur compounds, gas flow rate and ratio, reaction temperature, etc. on the yield of the coiled carbon fibers were examined. Morphology of the coiled carbon fiber was examined in detail and the growth mechanism is discussed. Some properties of the coiled carbon fibers were also examined.

\section{Experimental Procedure}

Commercial acetone-dissolved acetylene (97-99\%) was used without further purification as the carbon source. Fine $\mathrm{Ni}$ powder $(0.03-12 \mu \mathrm{m})$ was used as the catalyst for the growth of the coiled carbon fibers. A graphite substrate on which the $\mathrm{Ni}$ powder was dispersed by a spraying method was located in the central part of a horizontal reaction tube (quartz, $30 \mathrm{~mm}$ inner diameter $\times 550 \mathrm{~mm}$ length) which was heated from the outside by a nichrome element. The sulfur compound used as the impurity, such as thiophene, tetrahydrothiophene, butylmercaptan, diethylsulfide, hydrogen sulfide and carbon disulfide was saturated in the hydrogen carrier and introduced into the reaction tube. Unless otherwise described, reaction conditions used in this experiment were as follows: Impurity, thiophene; reaction temperature, $750^{\circ} \mathrm{C}$; reaction time, 15 min; acetylene flow rate, $30 \mathrm{sccm}(\mathrm{ml} / \mathrm{min})$; hydrogen flow rate, $70 \mathrm{sccm}$; and argon flow rate, $40 \mathrm{sccm}$. 


\section{Results and Discussion}

The obtained deposits were classified as coiled carbon fibers, straight fibers, powder and films using an optical microscope. The yield of the coiled carbon fibers was estimated from the ratio of the amounts of introduced carbon and that of the obtained coiled carbon fibers.

The effect of the gas flow rate of the sulfur compound impurity on the yield of the coiled carbon fibers ("coil yield" hereafter) is shown in Fig.1. The coiled carbon fibers were hardly obtained without the addition of the sulfur compound impurity. Using thiophene as an impurity, the yield of the coiled carbon fibers increased sharply with increasing gas flow rate of the thiophene and attained a maximum of about $50 \%$ at $0.35 \operatorname{sccm}(0.25$ mol\% in total flow gas) followed by decrease above that flow rate. The coiled carbon fibers were hardly obtained at a thiophene flow rate above $0.8 \mathrm{sccm}$ ( $0.57 \mathrm{mo} 1 \%$ in total flow gas). Similar relationships between the coil yield and impurity gas flow rate as using thiophene were observed for other impurites as can be seen in Fig.1. The optimum gas flow rate of various sulfur compound impurities at which maximum coil yield was obtained are shown in Table 1. Among various impurities, thiophene and thiophene derivatives gave a high coil yield. It may be considered that Ni particles are sulfurized in the reaction atmosphere, and properly sulfurized particles have good catalytic effect on the growth of the coiled carbon fibers. Excess addition of the impurity may act as a poison on the Ni catalyst.

The effect of the reaction temperature on the coil yield is shown in Fig.2, in which the impurity gas flow rate was fixed at the optimum flow rate to obtain the maximum coil yield (Fig.1). It can be seen that the maximum coil yield was obtained at a temperature of about $750^{\circ} \mathrm{C}$ irrespective of the kind of impurity and decreased sharply above or below this temperature.

The effect of the reaction atmosphere $\left(\mathrm{H}_{2} / \mathrm{Ar}\right)$ on the coil yield is shown in Fig.3. The maximum coil yield was obtained at a $\mathrm{H}_{2}$ concentration of 50-70 mol\% and decreased above or below this value.

The effect of reaction time on the coil yield is shown in Fig.4. The growth of coiled carbon fibers was observed after a 3 min reaction time and the yield increased with the reaction time and attained a constant value above $10 \mathrm{~min}$.

The relationship between the maximum coil yield and average diameter of the $\mathrm{Ni}$ particles used as the catalyst is shown in Fig.5. The highest coil yield was obtained using a $\mathrm{Ni}$ catalyst of $2-3 \mu \mathrm{m}$ in average diameter. This diameter is $1 / 2-1 / 10$ of the $\mathrm{Ni}$ catalysts observed on the tip part of the coiled carbon fibers as will be shown later.

The specific surface area of the coiled carbon fibers obtained using thiophene and hydrogen sulfide as the impurity was about $290 \mathrm{~m} / \mathrm{g}$ and 353 $\mathrm{m} / \mathrm{g}$, respectively, in which the surface area was measured by the BET method.

The volume electrical resistivity of the coiled carbon fibers was about one order of magnitude lower than that of acetylene black.

Representative coiled carbon fibers obtained using thiophene as the impurity are shown in Fig.6a. Generally, a obtained coiled carbon fiber had generally a constant coil pitch and coil diameter. The coiled carbon fibers were commonly combination coils in which two carbon fibers entwined with each other to form one carbon coil. However, a single carbon coil in which one carbon coil was formed from one carbon fiber or other types of combination carbon coils were also observed. Fig.6b shows an example in which one single coil having a large coil pitch and coil diameter contains another single coil having a small coil pitch and coil diameter. It is very interesting to know how or why the carbon fibers helical form coils. Fig. 7 shows the initial stage of the coiling process of the carbon fibers after $3 \mathrm{~min}$ of reaction time. It can be seen that two pieces of the carbon fibers of about $20 \mu \mathrm{m}$ in length grow from a cubic shaped $\mathrm{Ni}$ catalyst particle and begin to cur1 (arrow in Fig.7a). Sometimes, three pieces of the carbon fibers grew from one Ni catalyst grain (Fig.7b). Fig.8 shows a typical tip part of the coiled carbon fibers, A Ni particle used as a catalyst 
was sometimes observed in the middle part of the tip (arrow in Figs.8a and b). Two coiled carbon fibers grown from the $\mathrm{Ni}$ catalyst were entwined with each other to form one combination coil. (Figs. $8 \mathrm{~b}$ and $\mathrm{c}$ ).

Fig. 9 shows the tip of the loosely coiled carbon fibers obtained using tetrahydrothiophene as the impurity. It was sometimes observed that four carbon fibers (A, B, D, and E in Fig.9) grew initially in opposite directions from the $\mathrm{Ni}$ catalyst piece (arrow). The two fibers $\mathrm{A}$ and $\mathrm{B}$ were then joined together to form one fiber $C$. The length of A from the catalyst particle to the joining point is larger than the corresponding length of $B$. The combined fiber $C$ which curls has $A$ as its outer part and $B$ as its inner part. A similar situation is found in the case of fiber $D, E$ and $F$. These results suggest that coiled carbon fibers are formed because of the different growth rates of fibers from a $\mathrm{Ni}$ catalyst; the outer parts of the coils grow faster than the inner parts.

The $\mathrm{Ni}$ catalyst observed in the tip part of the coiled carbon fibers was analyzed using EPMA and the results are shown in Table 2 (The carbon content was not analyzed). It can be seen that the sulfur content in the $\mathrm{Ni}$ catalyst was $9-43$ at\% for the coiled carbon fibers depending on the kind of impurity and 1-3 at\% for the linear carbon fibers. The sulfur content of the Ni catalyst, which was observed on the tip of the coiled carbon fibers obtained at an optimum thiophene flow rate of $0.34 \mathrm{sccm}$, was 21 at\% and the value decreased above or below that optimum flow rate. These results suggest that the $\mathrm{Ni}$ catalyst was sulfurized by the sulfur compound impurity to form a solid solution of $\mathrm{Ni}-\mathrm{S}-(\mathrm{C})$, and the optimum sulfur content in the $\mathrm{Ni}$ catalyst for the growth of the coiled carbon fibers may be about 20 at\%. However, using a $\mathrm{Ni}{ }_{2} \mathrm{~S}$ powder (27 at\% S) as an impurity, no coiled carbon fibers were obtained. 2 There may be some difference in the reaction rate (sulfurizing rate) of the respective crystal plane of a $\mathrm{Ni}$ particle with sulfur. Some planes are more catalytic $(-20$ at\%) for the deposition of carbon and other planes are less catalytic (less sulfurized than 2-3 at\%). According1y, it may be considered that carbon fibers curl by the anisotropic deposition rate of carbon on the respective crystal planes of the $\mathrm{Ni}$ catalyst.

\section{References}

1) S. Motojima, S. Ueno, T. Hattori and K. Goto, App1. Phys. Lett., 54, 1001(1989).

2) S. Motojima, S. Ueno, T. Hattori, H. Iwanaga, J. Cryst. Growth, 96, 383(1989).

3) W.R. Davis, R.J. Slowson and G.R. Rigby, Nature, 171, 756(1953).

4) W.R. Davis, R.J. Slowson and G.R. Rigby, Trans. Brit. Ceram. Soc., $56,67(1957)$.

5) R.T.K. Baker, M.A. Barber, P.S. Harris, F.S. Feates and R.J. Waites, J. Catal., 26, 5i(1972).

6) L.S. Lobo and D.L. Trimm, J. Cata1., 29, 15(1973).

7) R.T.K. Baker and R.J. Waite, J. Catal., 37, 101(1975).

8) M. Hillert and N. Lang, Z. Krist., 111, 24(1958).

9) J. Caluszka and M.H. Back, Carbon, 22, 141(1984).

10) Y. Okada, K. Takeuchi, H. Yamanashi and H. Ushijima, J. Mater. Sci. Lett., $11,1715(1992)$.

11) S. Motojima, M. Kawaguchi, K. Nozaki, and H. Iwanaga, Appl. Phys. lett., $56,321(1990)$.

12) S. Motojima, M. Kawaguchi, K. Nozaki, and H. Iwanaga, Carbon, 29, 379(1991).

13) M. Kawaguchi, K. Nozaki, S. Motojima, and H. Iwanaga, J. Cryst. Growth, 118, 309(1991).

14) H. Iwanaga, M. Kawaguchi, and S. Motojima, Jpn. J. Appl. Phys., 32, 105(1993). 

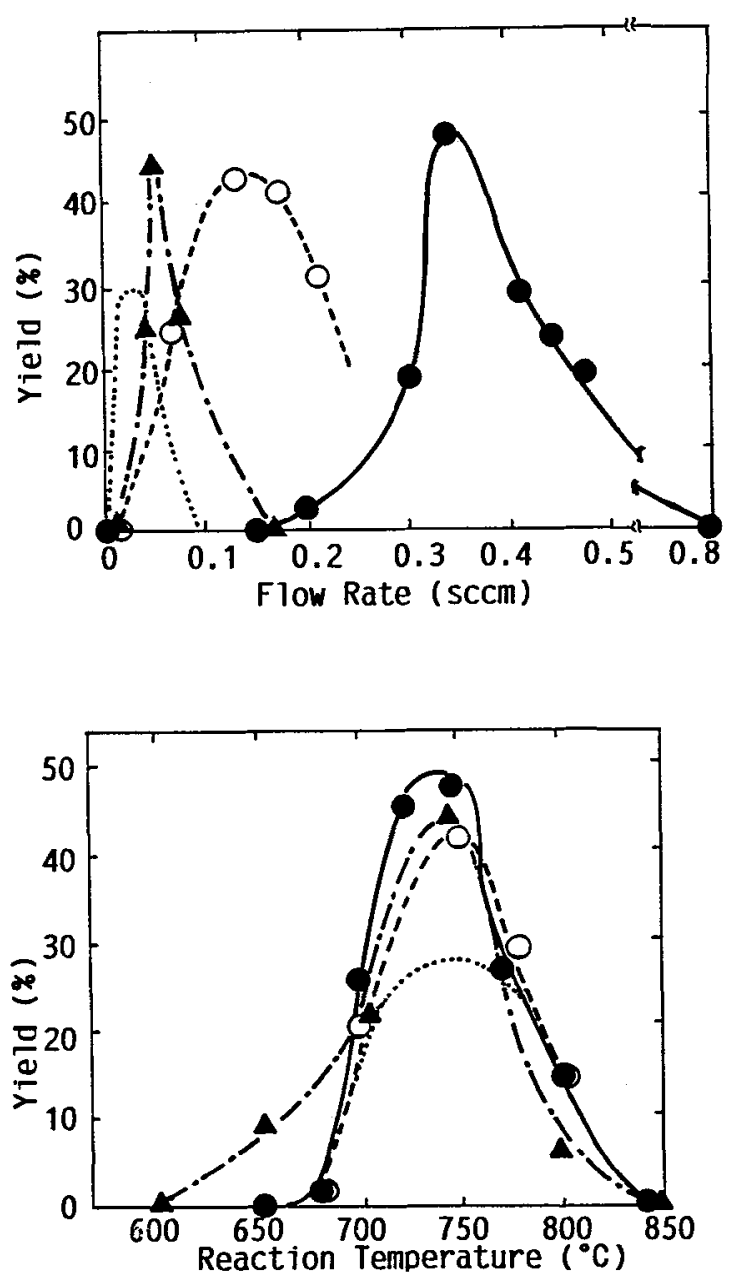

Fig.1. Effect of impurity gas flow rate on the yield of the coiled carbon fibers.

(C) Thiophene

$(\triangle)$ Tetrahydrothiophene

(O) Methylthiophene

(-....) Hydrogen disulfide
Fig.2. Effect of the reaction temperature on the coil yield.
(O) Thiophene
$(\triangle)$ Tetrahydrothiophene
(O) Methylthiophene
(.....) Hydrogen disulfide

Table 1. 0ptimum gas flow rate of impurity and maximum yield of the coiled carbon fibers.

\begin{tabular}{|l|c|c|}
\hline Impurity & $\begin{array}{l}\text { 0ptimum gas flow } \\
\text { rate(sccm) }\end{array}$ & $\begin{array}{c}\text { Maximum Coil } \\
\text { Yield (\%) }\end{array}$ \\
\hline Hydrogen Sulfide & 0.07 & 35 \\
Thiophene & 0.35 & 50 \\
Methylthiophene & 0.15 & 43 \\
Tetrahydrothiophene & 0.04 & 44 \\
Butylmercaptan & 0.09 & 41 \\
Diethylsulfide & 0.10 & 34 \\
Carbon Disulfide & 0.04 & 36 \\
\hline
\end{tabular}




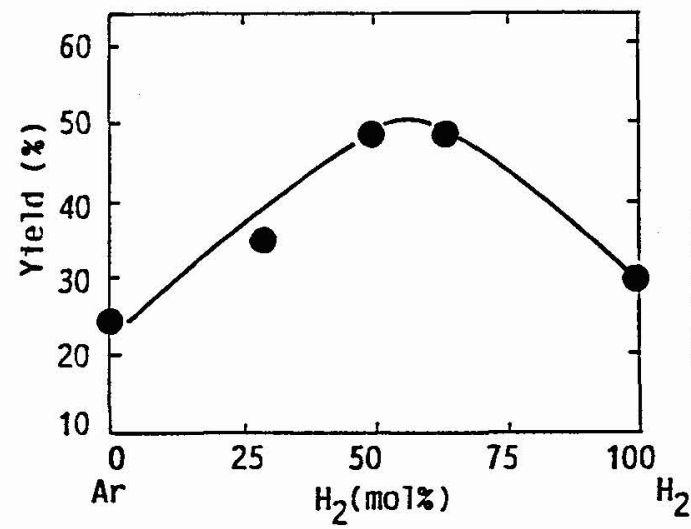

Fig.3. Effect of the reaction atmosphere $\left(\mathrm{H}_{2} / \mathrm{Ar}\right)$ on the coil yield.

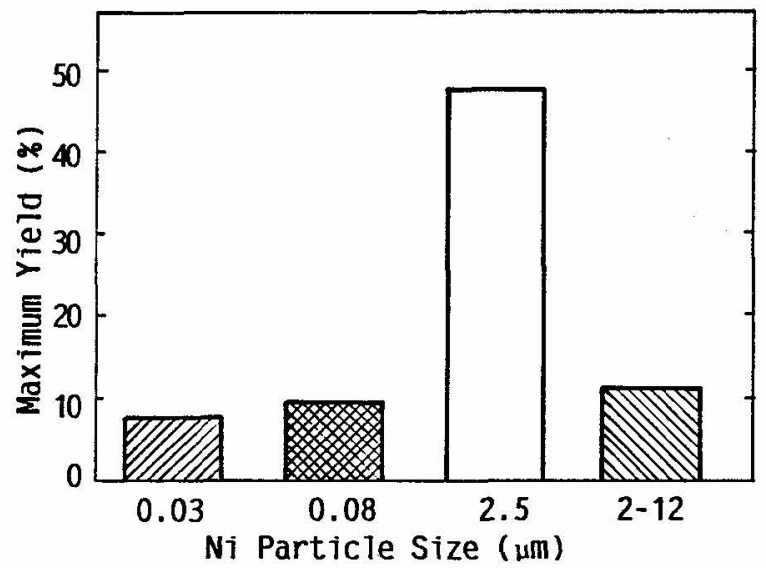

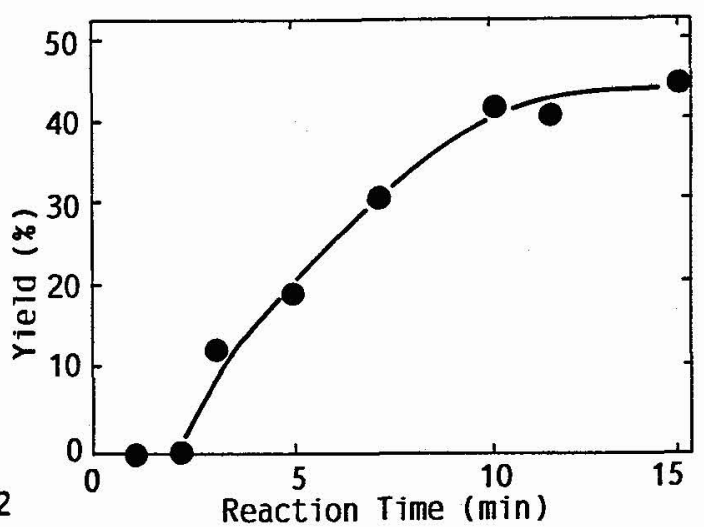

Fig.4. Effect of the reaction time on the coil yield.
Fig.5. Effect of particle size of $\mathrm{Ni}$ catalyst on the coil yield.

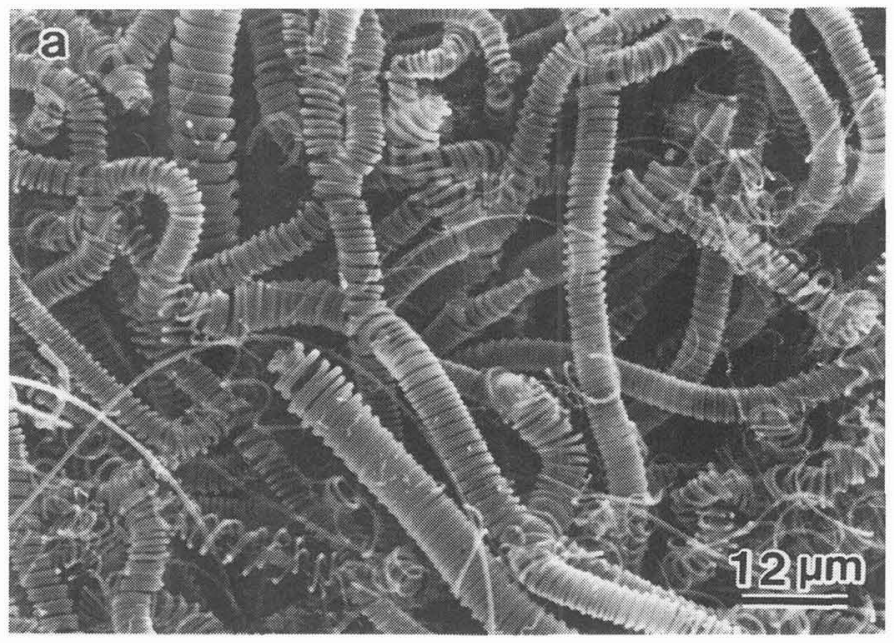

Fig.6. Representative coiled carbon fibers. 

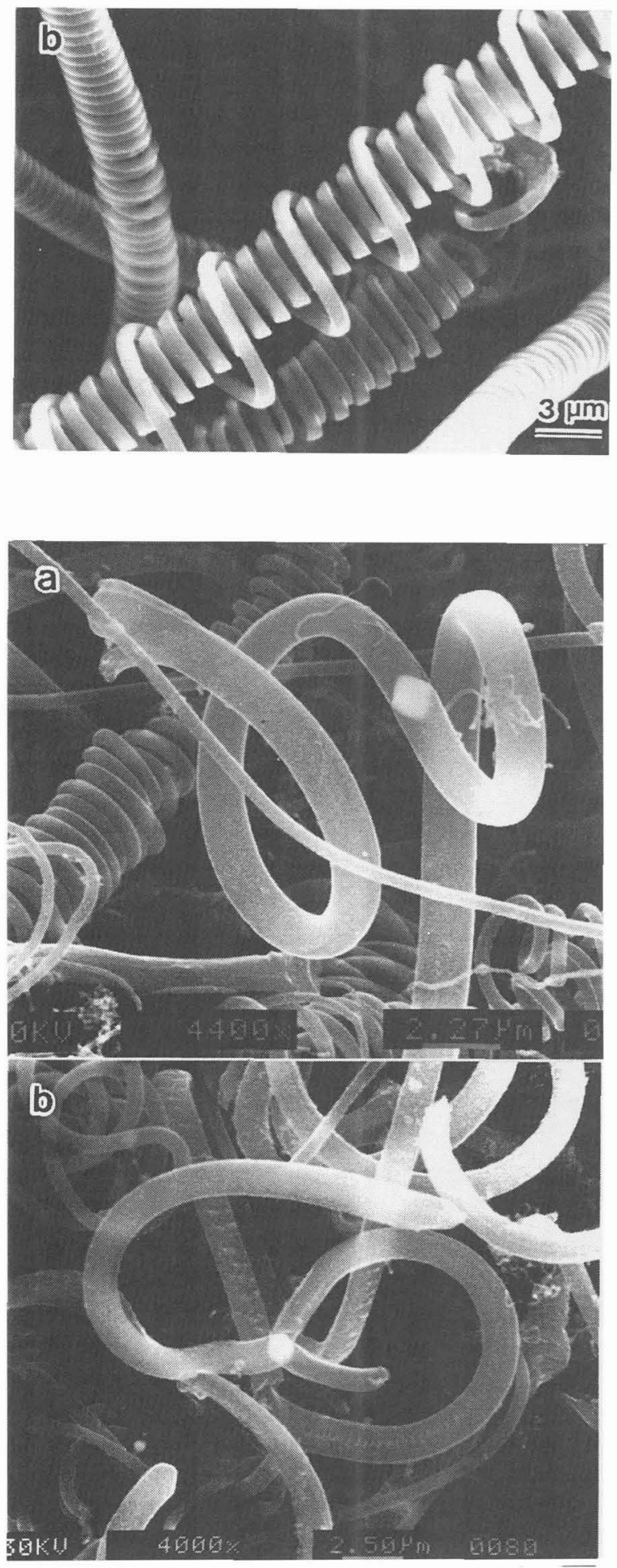

Fig.7. Initial stage of coiling of the carbon fibers. Reaction time: $3 \mathrm{~min}$. 

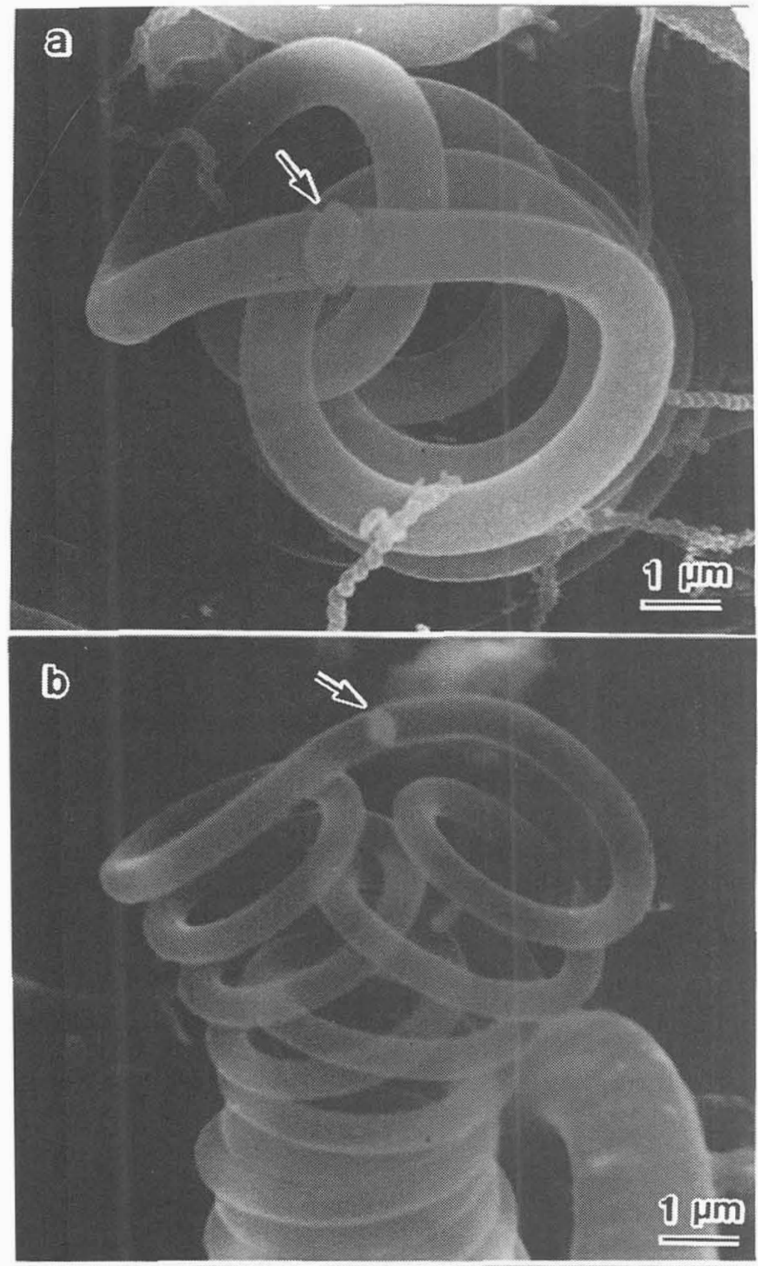

Fig.8. Tip of the coiled carbon fibers.

Arrow indicates the $\mathrm{Ni}$ catalyst particle.

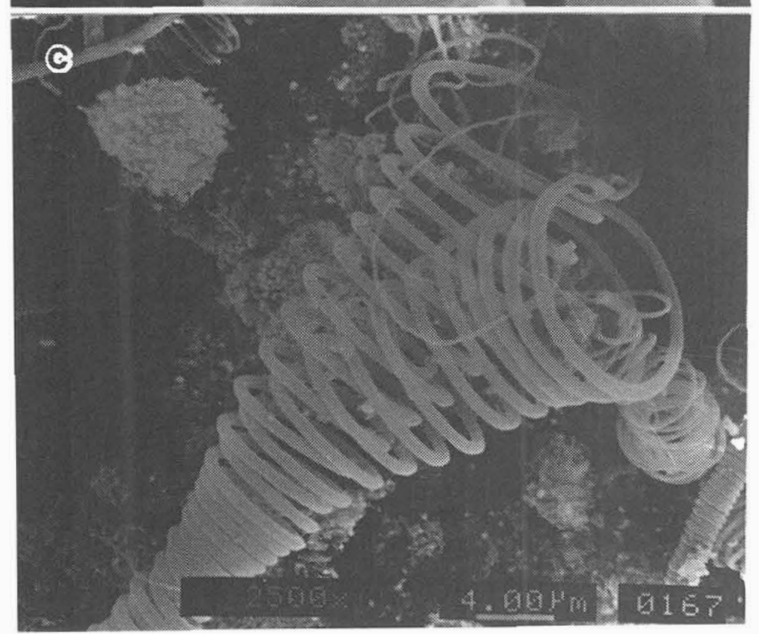




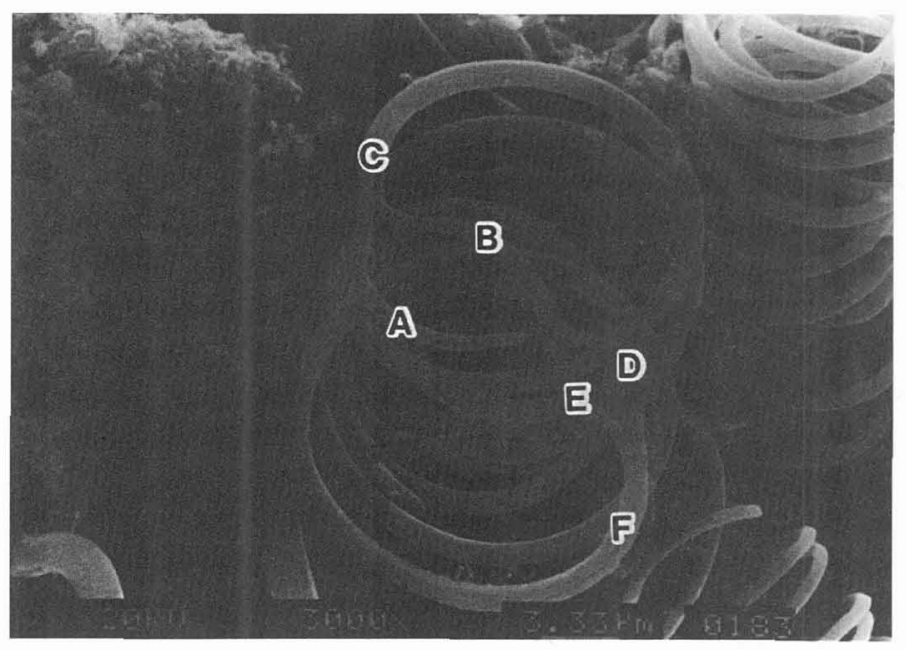

Fig.9. Tip of the coiled carbon fibers.

Impurity: tetrahydrothiophene.

Table 2. Composition of the Ni particle

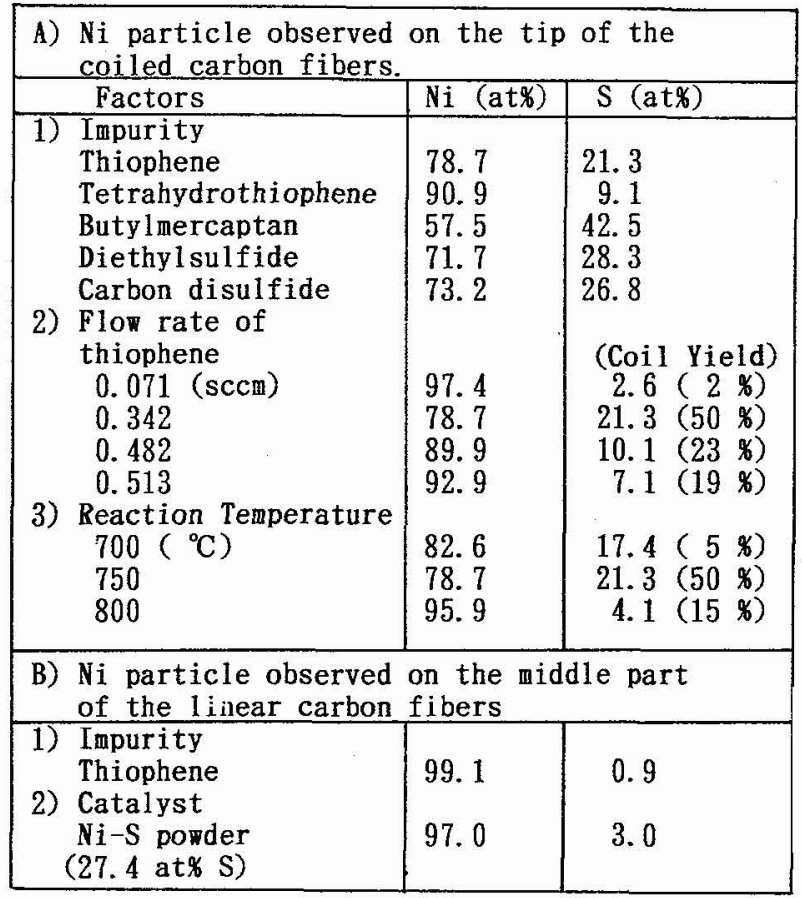

